\title{
Congregacionais e a Renovação Espiritual no Nordeste
}

\author{
Congregationalists and Spiritual Renewal in Brazilian Northeast region
}

Heitor Lamartine*

https://doi.org/10.29327/256659.12.2-6

Resumo:

Em meados de 1960, um clima de efervescência religiosa se alastrou por igrejas protestantes Brasil afora, conclamando uma renovação espiritual, que ganhou corpo através do Movimento de Renovação Espiritual. Os ventos dessa revitalização religiosa avançaram sobre o Nordeste, alcançando líderes e fiéis de várias denominações. No contexto nordestino, os batistas e congregacionais cumpriram importante papel para consolidação e difusão dessa tendência. Neste artigo, apresentamos um panorama histórico e sociológico acerca da renovação de segmentos do congregacionalismo e suas tensões na Paraíba e Pernambuco. Para tanto, além da literatura especializada consultada, realizamos pesquisa documental e entrevistas. Pretendemos, assim, sublinhar a importância desse movimento religioso para compreensão de facetas do protestantismo brasileiro e suas interfaces.

Palavras-chave: Congregacionalismo. Pentecostalização. Protestantismo. Renovação religiosa.

Abstract:

In the mid-1960s, an atmosphere of religious effervescence spread to Protestant churches throughout Brazil, calling for a spiritual renewal, which took shape through the Spiritual Renewal Movement. The winds of this religious revitalization advanced over the Brazilian Northeast region, reaching leaders and followers of various denominations. In the Northeastern context, Baptists and Congregationalistsplayed an important role in consolidating and spreading this trend. In this article, we present a historical and sociological overview of the renewal of segments of Congregacionalism and its tensions in Paraiba and Pernambuco states. Therefore, in addition to the specialized literature consulted, we have carried out documentary research and interviews. We intend, therefore, to underline the importance of this religious movement for the understanding of facets of Brazilian Protestantism and its interfaces.

Keywords: Congregacionalism; pentecostalization; Protestantism; religious renewal.

\section{Introdução}

Desde a inserção do Movimento Pentecostal no Brasil, ${ }^{1}$ a relação entre protestantes 'históricos' e pentecostais foi, na maior parte do tempo, marcada por

"Mestre em Ciências Sociais pela Universidade Federal de Campina Grande (UFCG). E-mail: heitor_lamartine@outlook.com. 
conflitos e tensões. Mas, em meados do século passado, as disputas entre esses segmentos religiosos começaram a arrefecer no país. Nessa época, o pentecostalismo teve amplo suporte dos seus fiéis para uma nova dinâmica de crescimento. Conforme Francisco C. Rolim (1985, p. 23), "não fosse a expansão pentecostal acelerando-se a partir da década de 1950, o protestantismo [leia-se, campo evangélico] não teria o crescimento que vem mostrando". A expansão pentecostal, certamente, contribuiu para reconfigurações no campo evangélico brasileiro.

Tal êxito do pentecostalismo no Brasil esteve associado com mudanças que a sociedade brasileira atravessou na esfera cultural, econômica, política, social e religiosa: crescimento demográfico nacional, intensificação das migrações internas e êxodo rural, urbanização e formação das periferias em grandes e médias cidades, retomada da industrialização do país, são alguns dos fatores que, direta e indiretamente, tiveram ressonância no cenário religioso brasileiro, contribuindo para enraizamento, crescimento e expansão pentecostal.

Deixando de ser uma minoria religiosa, os pentecostais vêm se tornando maioria numérica no campo evangélico e, também, frente a outras religiões. Como observam Leonildo S. Campos e Benjamín F. Gutiérrez (1996, p. 7), o Movimento Pentecostal "passou do rodapé da história religiosa e cultural para ser um concorrente pela hegemonia com o catolicismo no campo religioso brasileiro". Entretanto, seu avanço não se deu apenas em termos de adesões denominacionais; aliás, esse movimento religioso rompeu barreiras e transpassou limites do denominacionalismo existente.

O pentecostalismo converteu-se em um eminente paradigma de teologias e práticas religiosas para o cristianismo contemporâneo em várias nações e, em especial, no Brasil. Em meados do século XX, vimos ocorrer uma intensa assimilação de bens simbólicos pentecostais pelas principais denominações protestantes e até por setores católicos. Esse processo foi encarado de variadas maneiras, ora como revigoramento religioso, outra como ameaça à ortodoxia e identidade protestantes, causando situações paradoxais de renovação religiosa e crises denominacionais, retomada de crescimento e cismas.

Nessa dinâmica, o protestantismo brasileiro ${ }^{2}$ sofreu metamorfoses. Territórios confessionais foram recompostos e as interações entre indivíduos, instituições e universos simbólicos do campo evangélico sofreram profundas alterações, gestando o que estudiosos têm denominado de pentecostalização. Esse fenômeno 
sociorreligioso adquire maior expressão e visibilidade com o advento do Movimento de Renovação Espiritual ${ }^{3}$, que tomou diversas denominações e igrejas protestantes do país sob o anseio de revitalização religiosa.

Considerando essas questões, empreendemos pesquisa. Sob um prisma histórico-sociológico, nos empenhamos em analisar a gênese, desenvolvimento e desdobramentos atuais do Movimento de Renovação Espiritual Congregacionalista. Em correspondência com a abordagem adotada, realizamos um trabalho de pesquisa bibliográfica e documental, bem como, uma série de entrevistas com pastores e líderes congregacionais.

No decurso de nosso estudo exploratório, observamos que livros e trabalhos acadêmicos versando sobre essa temática possuem raras menções acerca dos impactos da renovação no congregacionalismo brasileiro. Todavia, esse segmento foi igualmente alcançado pelo Movimento de Renovação Espiritual, como o foram batistas, presbiterianos e metodistas. Prova disto é que no final da década de 1960, um grupo de pastores e fiéis congregacionais da Paraíba, Pernambuco e outros estados do Nordeste, seguiram pelas trilhas do Movimento Renovacionista que estava acontecendo no Brasil. À medida que o fenômeno pentecostalizante se difundiu nos círculos congregacionais, sobrelevaram-se as tensões, acarretando uma cisão denominacional e gerando dissidências nas igrejas locais.

Porém, não tardou para que os pastores e as Igrejas Congregacionais adeptas da renovação espiritual na região Nordeste - ou mesmo, pentecostalizadas - se reagrupassem denominacionalmente por meio da Aliança das Igrejas Evangélicas Congregacionais do Brasil (AIECB). Entremeios, surge a Igreja Evangélica Congregacional Vale da Bênção de Caruaru, que se tornaria baluarte e núcleo irradiador do congregacionalismo renovado de Pernambuco ao estrangeiro.

\section{O Movimento de Renovação Espiritual}

Por volta dos anos 1940, líderes e grupos vinculados à Igreja Metodista do Brasil começaram a pregar sobre a necessidade de um reavivamento. Em busca de uma efervescência religiosa semelhante àquela dos grandes avivamentos na Inglaterra e nos Estados Unidos do século XVIII. Esses arautos reavivalistas abriram caminho para um processo de assimilação de crenças e práticas pentecostais por parte das denominações e igrejas protestantes brasileiras (CAMPOS JÚNIOR, 2009). 
Nessa mesma época, a missionária Rosalee M. Appleby defendeu que, para superar a estagnação e frieza espiritual da comunidade batista em Minas Gerais e no Brasil, era necessária uma renovação espiritual. No decorrer dos anos, segundo Reinaldo A. Pereira, as pregações e escritos da senhora Appleby influenciaram pastores e lideres que se envolveram numa verdadeira campanha de revitalização religiosa da denominação batista.

Esta tendência logo se espalhou pelas igrejas batistas, congregacionais, presbiterianas e metodistas - não desconsiderando sua penetração entre os luteranos e católicos. Por meio de congressos, estudos bíblicos, folhetins, livretos, pregações, programas de rádio, reuniões de oração se propugnava a urgência de um reavivamento, uma renovação religiosa para o protestantismo brasileiro. Os pastores batistas José Rego do Nascimento e Enéas Tognini estão entre os principais responsáveis pela difusão da mensagem renovacionista pelo país. Na década de 1960, essa tendência ganha corpo no Movimento de Renovação Espiritual, através de encontros nacionais e regionais. Viajando pelo Brasil, os líderes renovacionistas pregavam sobre a importância da doutrina do Espírito Santo, a crença na atualidade dos dons espirituais e testemunhavam suas experiências pneumáticas entre seus confrades batistas, congregacionais, metodistas e presbiterianos - com um discurso religioso muito próximo e até semelhante ao dos pregadores pentecostais.

Essa onda carismática não representou apenas uma revitalização religiosa, como também provocou alterações no modelo de religiosidade, tradicionalmente, adotado pelas igrejas protestantes de missão no país ${ }^{4}$. Assim como o Movimento Pentecostal, a renovação espiritual tornou-se um movimento com força suficiente para criar novas realidades eclesiásticas, reestruturar teologias e substituir práticas cristalizadas por novas formas de crer, praticar e experimentar a fé protestante.

Após meio século de acirrados conflitos com os pentecostais, alas do protestantismo histórico e do catolicismo começaram a assimilar crenças e práticas que, outrora, foram caracteres quase exclusivos do pentecostalismo. Culminando no que o cientista social e teólogo Bernardo Luis Campos Morante (2016) chamou de "movimentos carismáticos não-pentecostais". Propositadamente ou não, os protestantes que transpuseram o abismo que os separava dos pentecostais, aproximaram-se e interiorizaram elementos do Movimento Pentecostal. Dessa 
maneira, acabaram redefinindo os termos das conexões e trocas simbólicas entre o protestantismo e o pentecostalismo.

Grosso modo, o movimento renovacionista tinha por objetivo revigorar as comunidades do protestantismo de missão, revitalizar a experiência religiosa dos fiéis e angariar novos conversos. No entanto, Thiago Moreira (2016, p. 22) observa que,

\footnotetext{
O advento desta expansão pentecostal, ou melhor, da experiência pentecostal em meio às igrejas protestantes tradicionais trouxe à baila novas formas de experenciar sua religiosidade que para uns seria uma forma mais livre, emocional e viva, para outros, uma forma herética, irracional e infantil. Assim, a questão do batismo no Espírito Santo e as possiveis manifestações que lhe seriam características apresentam-se como um desafio teológico e institucional $[\ldots]$.
}

Esse fenômeno sobreveio às searas protestantes como um tsunami, em certo sentido, 'invadindo-as'. Não obstante, pastores e leigos contrários aos 'excessos pentecostais' quiseram purgar suas denominações e comunidades dessa 'invasão pentecostal'. De modo que a emergência do Movimento de Renovação Espiritual foi acompanhada por acaloradas discussões em concílios denominacionais e assembleias locais, várias dessas resultando em divisões institucionais e comunitárias. Na tentativa de preservar as tradições denominacionais, convenções de ministros e reuniões extraordinárias foram acionadas para intimar pastores e crentes adeptos da renovação espiritual.

Muitos desses indivíduos foram expulsos e outros tantos, espontaneamente, decidiram deixar suas comunidades, por não abrirem mão das crenças e da experiência carismática. Os dissidentes se mobilizaram, dando origem às chamadas igrejas renovadas, que também formaram redes de filiação à semelhança de denominações protestantes e pentecostais já estabelecidas.

\section{E os ventos da renovação sopraram sobre os protestantes nordestinos}

Enfrentando os desafios de uma recomposição denominacional, diversos pastores e igrejas congregacionais do Nordeste também foram afetados pelo Movimento de Renovação Espiritual. Seguindo a narrativa oficial, por volta de 1959, um clima de efervescência religiosa com tonalidades pentecostais tomou a $1^{\text {a }}$ Igreja Congregacional de João Pessoa, no estado da Paraíba. A partir da pregação 
do pastor metodista Dorival Rodrigues Bewlke, por ocasião da festividade da União Auxiliadora Feminina, aquela comunidade viu aumentar o número de "conversões, de mudança de hábito em muitos membros da igreja. A Mocidade era ativa, a Auxiliadora atuante, a Escola Dominical dinâmica, o Evangelho pregado com autoridade, almas sendo salvas e o Reino de Deus se expandindo" (SANTOS, 2006, p. 231).

Repetindo padrões observados em igrejas protestantes impactadas pela renovação espiritual, no ano de 1962, cerca de 80 fiéis deixaram essa Igreja Congregacional de João Pessoa para se integrarem à Assembleia de Deus, causando forte abalo naquela comunidade. Mesmo com a baixa de membros, os congregacionais permaneceram envoltos numa aura de renovação religiosa que, mais tarde, contagiou outras igrejas congregacionais paraibanas e pernambucanas.

Segundo o pastor e memorialista Geraldo Batista dos Santos (2006, p. 231),

[...] o grupo remanescente, na liderança do pastor Jônatas Ferreira Catão, não desanimou, nem tergiversou. Pelo contrário, continuou exercendo o ministério da oração, a prática de uma vida à disposição do Senhor da Obra: evangelizando e servindo. Deus honrou, abençoou e triplicou a membresia da igreja, tornando-a forte numérica e espiritualmente. Muitos desses irmãos tiveram vidas renovadas, com a bênção do batismo com o Espírito - inclusive o pastor Catão -, exercendo dons, ganhando almas, vivendo plenamente o Evangelho. Desde, então, o reverendo Jônatas Ferreira Catão e sua igreja promoveram uma busca pelo "avivamento espiritual".

Enquanto isso, na capital pernambucana, os batistas também se engajaram no Movimento de Renovação Espiritual. Em 1961, o reverendo José Rego do Nascimento realizou uma série de conferências em igrejas e seminários teológicos do Recife, por ocasião do Congresso da Juventude Batista Pernambucana. O evento reuniu pastores, lideranças leigas e jovens de várias denominações para ouvir a pregação desse 'profeta' do renovacionismo.

Segundo Rosivaldo de Araújo (2013, p. 32),

O pastor José Rego voltou para Belo Horizonte, porém muitos segmentos evangélicos do Recife foram incendiados pelo poder de Deus. Ninguém mais conseguia viver aquela vida antiga, morna, acomodada e sem unção. Os batismos no Espírito Santo começaram a se suceder naquelas igrejas tradicionais e conservadoras, entre pastores, líderes e os crentes em geral. 
A Igreja Batista de Casa Amarela tornou-se outro centro irradiador da renovação protestante no Nordeste. A partir dela e da influência de seu pastor, Rosivaldo de Araújo, várias igrejas protestantes de Pernambuco começaram a promover reuniões de oração e vigílias, os sermões pregados adquiriram tons avivalistas e cultos eram marcados por pessoas se convertendo, brados de aleluia e glória a Deus, fiéis sendo batizados com o Espírito Santo, falando n'outras línguas, tendo visões, declarando profecias ou sendo curados miraculosamente à semelhança dos pentecostais.

Nesse período, as articulações e contatos entre os líderes renovacionistas do país se tornaram mais frequentes. Pastores e igrejas renovadas buscavam estar sincronizados com o Movimento Renovacionista em âmbito nacional e regional. Os batistas protagonizaram Encontros Nacionais e Regionais de Renovação Espiritual, realizados anualmente em diferentes estados, contando até com a participação de pregadores pentecostais, como o bispo Robert McAlister. Era um momento em que se buscava esclarecimento das doutrinaseexperiências pentecostais, bem como, sobre o processo de interiorização e incorporação à teologia e práxis do protestantismo tradicional (ARAÚJO, 2013).

Essa disposição do campo evangélico permitiu maior fluxo e contatos entre fiéis de diferentes denominações e, consequentemente, de trocas simbólicas. Os eventos interdenominacionais realizados serviram como espaços desterritorializados, por não estarem sujeitos ao domínio de denominações ou igrejas específicas. Conforme Araújo (2013), o caráter interdenominacional do Movimento de Renovação Espiritual entre os nordestinos, culminou na criação do Comitê de Avivamento do Nordeste, reunindo batistas, congregacionais, metodistas e presbiterianos independentes.

Entremeios, o pastor Jônatas Ferreira Catão, acompanhado por outros pastores, líderes leigos e fiéis congregacionais aderiram de vez ao Movimento Renovacionista, participando dos encontros interdenominacionais e disseminando a mensagem da renovação nas suas comunidades.

Conforme Santos (2006, p. 232),

Nos idos de 1964 surgiu no seio dos batistas o Movimento de Renovação Espiritual e muitas igrejas foram sacudidas pelo poder do Espírito Santo para a realização de uma grande obra. Anossa igreja se identificou muito bem com a linha de Renovação Espiritual, porque liderada por homens de Deus de muito conceito e de bom testemunho, a exemplo dos pastores José Rego do Nascimento, Enéas Tognini, Rosivaldo de Araújo, Josué Santana [...] Havia ale- 
gria no meio do povo de Deus e as igrejas promoviam encontros de renovação, com o envolvimento de muitos pastores, líderes, cantores e igrejas. Era uma festa constante, com o povo arregimentado, orando, cantando e vivendo o evangelho com muita intensidade. Como dissemos, o volume maior de igrejas era do segmento batista, entretanto, na Paraíba, tínhamos na Igreja Congregacional de João Pessoa o seu maior expoente, o epicentro do movimento, com uma atuação marcante na capital, com reflexos em toda a região.

As conexões interdenominacionais foram imprescindiveis para fortalecimento do emergente movimento e, também, para o processo de interiorização teológica, assimilação e tradução cultural dos bens simbólicos e práticas pentecostais pelos protestantes. A natureza interdenominacional do Movimento Renovacionista permitiu que teólogos renomados, como Enéas Tognini, contribuíssem para formulação doutrinária das crenças e práticas assimiladas, constituindo assim uma importante etapa da legitimação para as igrejas renovadas.

A recomposição do universo simbólico congregacional, assim como dos demais grupos carismáticos, precisava de aportes na própria tradição congregacionalista, sem a qual seria inviável manter a identificação dos renovacionistas com o congregacionalismo.

Segundo Moreira (2016, p. 35),

Para os adeptos da renovação espiritual o objetivo era "renovar", ou seja, partir de algo que já estava posto, um protestantismo que era considerado "frio" e com uma espiritualidade escassa (ou até ausente): "igrejas que existem, mas que dormem embaladas pelo comodismo e pela inatividade". Tratava-se de conduzir tal protestantismo a uma dimensão experiencial que promovesse o despertar da espiritualidade tal como na igreja primitiva (era apostólica), um "retorno ao Pentecostes", e não de inovar.

A adesão desse segmento congregacionalista ao Movimento de Renovação Espiritual pode ser considerada, primeiramente, como uma consequência do reconhecimento da vivência e da experiência pentecostal-carismática de pastores, fiéis e igrejas congregacionais. Mas, ainda há dois aspectos interessantes para pensar acerca dessa abertura para pentecostalização.

Partindo de alguns insights pontuados por Enéas Tognini (1986), sublinhamos que a aceitação da renovação espiritual, se não assimilada pelo protestantismo brasileiro, poderia ter como resultado imediato a transferência de fiéis e até pastores para denominações e igrejas pentecostais. Outro desdobramento 
dessa decisão diz respeito ao modo como protestantes históricos continuariam lidando com um novo modelo de religiosidade oferecido no mercado religioso - a saber, aquele que prometia experiências mais emocionais com o sagrado, com destaque para o usufruto dos dons do Espírito Santo.

Olhando por esse prisma, ao aceitar os princípios da renovação espiritual, os líderes congregacionais estariam mudando os rumos do congregacionalismo brasileiro. Aqueles que o fizeram assimilaram diversos elementos simbólicos do Movimento Pentecostal que se tornaram temas e objetos transversais do universo religioso das igrejas congregacionais renovadas, condicionando suas doutrinas, representações, símbolos, práticas, enfim sua teologia, religiosidade e experiência religiosa.

\section{Forjando uma Aliança Congregacional}

Conforme Manoel B. Santana Filho (2011, p. 5), havia "um desejo ardente e também sincero de um avivamento espiritual no meio das igrejas da União"5. Por outro lado, existia uma preocupação em conservar a tradição congregacionalista iniciada pelo missionário Robert Reid Kalley, afim de preservar seus princípios teológicos e, principalmente, eclesiásticos.

No entanto, assim como aconteceu com outras denominações protestantes, a renovação espiritual entre os congregacionais desencadeou reações adversas. A proliferação das crenças e práticas renovacionistas no interior da União Congregacional, despertou a oposição de um grupo de pastores, dada sua semelhança com o universo simbólico pentecostal. Para o qual, a renovação espiritual representava uma ameaça à ortodoxia e ao modelo de culto congregacional. As práticas relacionadas com a renovação espiritual foram consideradas por alguns como antagônicas ao ethos congregacional e à teologia reformada-kalleyana. Logo, os líderes e fiéis renovacionistas seriam estigmatizados como facciosos que ensinavam 'heresias pentecostais', degenerando a tradição protestante e, mais especificamente, congregacional.

No mês de junho de 1967, a Igreja Evangélica Congregacional de Patos, Paraíba, pastoreada pelo reverendo José Quaresma de Mendonça, sediou dois congressos, um organizado pelo departamento feminino e outro pela juventude. As preleções do missionário Gerson Barbosa de Menezes foram acompanhadas de conversões, confissões de pecados e ‘batismos com o Espírito Santo'. A reper- 
cussão desses eventos parece ter sido o estopim para que o setor congregacionalista conservador combatesse abertamente o renovacionismo entre os congregacionais, numa ação de feitios inquisitoriais (SANTOS, 2006).

Foi então convocado o $18^{\circ}$ Concílio Geral (Extraordinário) da União Congregacional, sediado em Feira de Santana, estado da Bahia, que se realizaria no final do mês de julho. Segundo a versão dos renovacionistas, a pauta principal da reunião foi a questão da renovação espiritual entre os congregacionais. Uma comissão especial havia sido encarregada de apresentar um relatório sobre o assunto aos participantes da assembleia. Para Santos (2006, p. 235),

O documento era um verdadeiro libelo acusatório às igrejas que estavam trabalhando de forma avivada e dependente de Deus: taxaram-nos de pentecostais de última hora, de xangozeiros, de embusteiros, de promotores de baixo espiritismo, de hereges, de anátemas, provocadores da desordem no culto, de profetas falsos, entre outros adjetivos.

O parecer da comissão recomendava, então, a exclusão de igrejas e pastores da fraternidade denominacional. Durante o concilio foi vetado o direito de resposta aos renovacionistas, que sequer tiveram tempo para se articular com os membros da assembleia antes da votação. Ao final da reunião, foi deferida a exclusão de sete igrejas filiadas da Paraíba, Pernambuco e Rio Grande do Norte, além dos seus respectivos pastores. Foram excluídos, assim, os pastores Jônatas Ferreira Catão, José Quaresma de Mendonça, Isaías Correia dos Santos, Moisés Francisco de Melo, Raul de Souza Costa, João Barbosa de Lucena e Roberto Augusto de Souza.

Partindo das considerações de Pereira (2011), entendemos que esse 'processo inquisitorial' não foi um ato isolado, tampouco uma reação somente aos renovacionistas desligados naquela ocasião. Consistiu numa tentativa de legitimação da religiosidade tradicional - e, cessacionista -, ao mesmo tempo, era uma via para interromper o processo de pentecostalização que estava em curso naquela e em outras denominações protestantes brasileiras. Esse cerceamento religioso, construído nos meandros do poder, "fez com que a prática da vigilância tivesse equivalência com a prática persecutória e inquisitória” (PEREIRA, 2011, p. 92), comum na história protestante e, particularmente, no contexto do Movimento de Renovação Espiritual do protestantismo brasileiro. 
O congregacionalismo renovado também foi encarado como uma degeneração doutrinária e, consequentemente, da identidade congregacionalista. Para aqueles que se arrogaram como representantes da tradição confessional, a renovação espiritual seria uma profanação dessa ortodoxia.

Como explica Carlos H. P. Souza (2013, p. 13),

Para estes grupos a pentecostalização representa a influência da crença pentecostal no reforço de concepções mágicas do mundo nas igrejas históricas. Isto ocorreria em consequência da predominância de concepções encantadas fortemente presentes no "ambiente pentecostal" o que explica o fenômeno ocorrido nas igrejas históricas.

Nesse sentido, a pentecostalização não apenas engendrou mudanças na cultura religiosa congregacional, como também desvelou disputas que estavam germinando alguns anos antes, desde a inserção pentecostal no país e assimilação de tendências carismáticas por outras igrejas protestantes. Essas mudanças davam margem para conflitos internos que irromperam com inúmeras cisões denominacionais decorrentes da questão pentecostalizante. Pôr em suspeição, estigmatizar, perseguir e excluir foram instrumentos para atacar e, se possivel, extirpar o mal que incomodava e ameaçava o establishment protestante e, por extensão, congregacionalista.

Assim foi com os batistas renovados que, mediante a exclusão da Convenção Batista Brasileira fundaram a Convenção Batista Nacional. Não seria diferente com os congregacionais, que já contavam com um corpo de pastores instituídos e templos disponíveis para reunir os fiéis adeptos da renovação espiritual.

O concílio de Feira de Santana refletia a tentativa de impedir o avanço da pentecostalização e conter os agentes pentecostalizantes que trabalhavam para renovar o congregacionalismo brasileiro. Diante da resolução daquela assembleia, restou aos congregacionais renovacionistas o mesmo caminho que outros protestantes renovados excluídos, fundar uma nova denominação.

Conforme Santos (2006, p. 237), a sugestão de "reunir os excluídos num grupo organizado, com características denominacionais, com estatuto, regimento interno, diretorias" partiu do pastor Jônatas Ferreira Catão. Ele se tornou principal agente na tarefa de arregimentar pastores e igrejas para formar uma nova denominação congregacionalista. Com seu carisma pessoal e capacidade de arti- 
culação não lhe foi dificil cumprir tal missão. Visitas foram realizadas aos líderes e igrejas congregacionais que comungavam dos ideais e práticas renovacionistas que, após desligarem-se da União, juntaram-se ao grupo excluído.

Em 13 de agosto de 1967, as delegações das igrejas congregacionais renovadas se reuniram na Igreja Evangélica Congregacional de Campina Grande para discutir sobre a criação de uma nova entidade denominacional que lhes representasse. Dando continuidade ao concílio, no dia seguinte, foi fundada a Aliança de Igrejas Evangélicas Congregacionais do Brasil.

Assim, a Aliança Congregacional foi constituída como organismo denominacional representante das igrejas congregacionais de linha renovada no Nordeste brasileiro, assumindo o papel de difundir, expandir e solidificar o congregacionalismo carismático na região e além. Entusiasticamente, a esposa de um dos líderes renovacionistas congregacionais, d. Iraci Silva de Mendonça (2007, p. 42) relata que

Desde então, as igrejas tomaram grande impulso espiritual. Agora com uma nova visão, na doutrina (com ensinamentos intensivos), na comunhão, no amor, na firmeza, na dedicação, enfim: mais sede de salvação pelas almas perdidas. Foi uma verdadeira revolução espiritual, parecendo até que havia surgido uma nova igreja, que dia-a-dia crescia e se fortalecia.

E, assim como outras denominações do Movimento de Renovação Espiritual que surgiam, os congregacionais renovacionistas cantavam a canção do reverendo Rosivaldo de Araújo: “Ninguém detém é obra santa! Nem Satã, nem o mundo todo podem apagar esse ardor...”.

Mesmo com a recomposição nacional da União das Igrejas Evangélicas Congregacionais do Brasil, em 1969, que tinha o propósito de reunir 'todas' igrejas congregacionais do país em um só órgão denominacional, os renovados permaneceram de fora dos quadros da nova denominação. Escrevendo sobre a história do congregacionalismo brasileiro, os reverendos Salustiano P. César (1983) e Manoel Porto Filho (1997) omitiram o racha com os renovados. No entanto, deixaram nas entrelinhas que os 'autênticos congregacionais' estariam integrados na União Congregacional, como únicos e verdadeiros herdeiros dos pioneiros congregacionais no Brasil. 


\section{No Vale da Bênção: a renovação congregacional na "Capital do Agreste" per- nambucano}

Em fins do século XIX, a cidade de Caruaru, no interior de Pernambuco, recebia além da estação ferroviária da Great Western, os primeiros missionários congregacionais. A despeito dos entraves, a Primeira Igreja Congregacional de Caruaru foi implantada. Entre avanços e percalços, essa comunidade se solidificou e cresceu significativamente, especialmente, sob a liderança do reverendo Júlio Leitão de Melo. Estima-se que, na década de 1960, havia cerca de quinhentos fiéis membros dessa igreja ${ }^{6}$.

Cumpre frisar que desde que se estabeleceram em Caruaru, os congregacionais tiveram de enfrentar o enorme desafio de romper com o monopólio católico, como demonstraram Joyce E. W. Every-Clayton e Araújo (1998). Apesar da predominância do catolicismo, desde 1920, a presença protestante já se fazia notória na sociedade caruaruense. Além dos congregacionais, outras missões protestantes começaram suas atividades na cidade, culminando na fundação da Primeira Igreja Batista (1923), da Primeira Igreja Presbiteriana do Brasil (1927), da Assembleia de Deus (1935), da Igreja de Cristo Pentecostal do Brasil (1947), entre outras.

Convém pontuar que, em meados do século XX, Caruaru despontava no agreste pernambucano como centro gravitacional de comércio, cultura e educação ${ }^{7}$. Jovens, adultos e famílias inteiras, por diferentes motivações, afluíram das zonas rurais e cidades circunvizinhas para a juvenil "Princesa do Agreste". O crescimento demográfico foi acompanhado por profundas mudanças socioculturais, como o desenvolvimento comércio e a indústria local. Sob a onda do desenvolvimentismo nacional, Caruaru recebeu as inovações do cinema, do rádio, da arquitetura e da urbanização, bem como, os colégios ginasiais e as primeiras faculdades da região. Por meio de discursos, imagens e práticas sociais, foi então inventada a "Capital do Agreste".

Essas metamorfoses parecem ter sido acompanhadas por uma intensificação do processo de pluralização do campo religioso local, aliando-se o crescimento urbano, que atraía individuos com a emergência de novas propostas de religiosidade. Como salientou Rolim (1985), os fenômenos de êxodo rural, urbanização, industrialização e migração, frequentemente, têm sido indicados como 
fatores importantes para entendermos o crescimento e a expansão do protestantismo e, sobretudo, do pentecostalismo.

Essa inferência encontra respaldo no fato de que, com menos tempo de atuação na cidade, os assembleianos logo ultrapassaram numericamente a comunidade congregacional e, também, em termos de expansão territorial, contando com três templos da Assembleia de Deus (RODRIGUES,1968).

Essas mudanças, certamente, afetaram na lógica e no funcionamento das igrejas evangélicas da cidade. Assim, é possivel inferir que os pentecostais experimentaram um acelerado crescimento e expansão, no lastro de transformações socioculturais mais amplas. Algo que acreditamos ter contribuído para tornar o ambiente sociorreligioso propício à recepção do Movimento de Renovação Espiritual entre os protestantes caruaruenses e, especialmente, os congregacionais.

Não podemos esquecer que um clima avivalista tomava conta das igrejas congregacionais paraibanas e pernambucanas, das capitais ao agreste. Na medida em que o Movimento Renovacionista crescia com a adesão de pastores e fiéis de várias denominações protestantes, aumentava sua influência, despertando outros tantos para a mensagem renovacionista, que também chegou à capital do agreste pernambucano.

Conforme relata o pastor Anacleto Inácio da Silva ${ }^{8}$, nos idos de 1965, a Primeira Igreja Congregacional de Caruaru recebeu o pastor Josué Santana, importante líder batista do movimento renovacionista na cidade do Recife. Durante sua visita, o reverendo ministrou uma série de estudos sobre despertamento espiritual para os fiéis congregacionais e mensagens evangelísticas nos cultos públicos. Nosso entrevistado acrescentou que

Em 1966 acontece mais um Encontro de Renovação Espiritual, desta feita, na cidade de Recife, tendo como palestrante o reverendo Enéas Tognini. Estiveram presentes a este Encontro vários pastores congregacionais. Posso citar dois, que acredito que tiveram importância, o Roberto Augusto de Souza, que era o pastor da Igreja Congregacional em Casa Amarela em Recife, e o pastor Edgar Leitão de Albuquerque, que era o pastor da Primeira Igreja [Evangélica Congregacional] de Caruaru. Então, esses homens beberam na fonte da renovação. Esses e outros tantos, já vinham há anos atrás buscando um avivamento genuíno, estudando sobre o assunto, orando por isso, não é? Então, por isso que quando o movimento acontece, as portas se abrem no seio congregacional 
para receber o movimento. Era algo que eles já vinham buscando algum tempo atrás. [Acréscimo nosso].

Em janeiro de 1967, a cidade do Recife sediou o IV Encontro Nacional de Renovação Espiritual. ${ }^{9}$ Uma caravana formada por fiéis da Primeira Igreja Congregacional de Caruaru foi organizada pelo presbítero Caetano Antônio da Silva para participar do evento. Ao regressar do encontro, o grupo se reuniu para orar no pátio da residência do presbítero citado. Depois daquela primeira reunião, outras se sucederam. Geralmente, ocorriam após os cultos noturnos da referida igreja, estendendo-se pela madrugada.

Daniel Tenório Siqueira (2007, p. 15) registra ainda que,

[...] aqueles irmãos passam a reunir-se regularmente naquele local, onde, certo dia, diante da visitação poderosa do Espírito Santo, o irmão José Braz declarou: "Isto é um vale de bênção!". De fato, aquela declaração expressava na íntegra, a nova e indizivel experiência que aqueles irmãos estavam vivendo. Desde então, o pátio da casa do presbitero Caetano passou a ser chamado de "VALE DA BÊNÇÃO”.

A exclamação daquele fiel, consciente ou inconscientemente, reportou-se ao tema do IV Encontro Nacional de Renovação Espiritual, Juntos no Vale da Bênção, do qual tinha participado o grupo simpático à renovação espiritual ${ }^{10}$. Essa experiência hierofânica do "vale de bênção" foi, ao mesmo tempo, transformadora da religiosidade daqueles congregacionais e fundante para o movimento renovacionista local que mais tarde daria origem à Primeira Igreja Evangélica Congregacional Vale da Bênção. O grupo carismático detinha, a partir de então, um fundamento de legitimidade pela vinculação a um poder extemporâneo outorgado pela própria divindade, o Espírito Santo e, também, baseada no princípio da sola Scriptura (SANTOS, 2014). De modo geral, a expressão "vale da bênção" seria tomada como símbolo da ala carismática congregacional.

Araújo (2013) relata que chegou a participar de algumas daquelas reuniões no pátio do presbítero Caetano. Ele enfatiza a presença de pessoas de outras denominações, desde assembleianos até batistas afeiçoados aos ideais renovacionistas. Também era comum encontrar pessoas não evangélicas, algumas das quais acabavam se convertendo à fé protestante. Dentro de pouco tempo, esses cultos já contavam com aproximadamente quarenta pessoas. 
Devido à continuidade das reuniões carismáticas, a liderança congregacional caruaruense propôs, em reunião ordinária, a convocação para os fiéis retornarem, caso contrário, seriam excluídos do rol de membros da Igreja Congregacional.

Siqueira $(2007$, p. 13) nos informa que,

O pastor Edgard Leitão de Albuquerque (na época pastor da Primeira Igreja Evangélica Congregacional) tentou contornar a situação, e, em uma reunião ordinária presidida por ele, no dia 06 de agosto de 1967, na qual foi determinada uma data de retorno dos 38 irmãos à igreja. Os que não retornassem estariam automaticamente desligados do rol de membros da igreja. O tempo determinado se passou, e na reunião do mês seguinte, 03 de setembro de 1967, houve o retorno dos irmãos José Brás de Araújo, José Antônio de Oliveira e a irmã Maria José de Oliveira. Os outros foram desligados do rol de membros da igreja, em um total de 35 irmãos $[\ldots]$.

O grupo renovacionista se afastou voluntariamente da Igreja Congregacional de Caruaru, deixando a tutela religiosa do reverendo Edgard Leitão. Como observou Antônio G. Mendonça (2004, p. 33), "quanto mais rígida e sujeita a doutrinas estabelecidas e consolidadas for uma instituição religiosa, mais sujeita estará a divisões ocasionadas pela necessidade de liberação do sagrado". Diante da impossibilidade de perpetuar seus vínculos, a criação de uma nova comunidade com elementos da teologia reformada-kalleyana e eclesiologia congregacional acrescida das ênfases pentecostais-carismáticas seria a via para que o grupo renovacionista se reconhecesse como mantenedor da tradição congregacionalista brasileira. Além do mais, a concepção congregacionalista de igreja, como corpo de fiéis reunidos localmente, dava margem para formação do novo agrupamento sem maiores dificuldades. Dos excluídos, 28 pessoas dariam início à "Congregação Congregacional Vale da Bênção". Não tardou para que a pequena comunidade fosse inserida num processo de institucionalização. No fluxo da Renovação Espiritual, a "Congregação Vale da Bênção" recebeu os pastores congregacionais renovacionistas Jônatas Ferreira Catão e Raul de Souza Costa, que estavam arregimentando outros pastores e igrejas para criação da nova denominação congregacional renovada.

Assim, dias após a fundação da Aliança Congregacional, era inaugurada e emancipada a Igreja Evangélica Congregacional Caruaruense, em 19 de agosto de 1967. Os congregacionais renovacionistas de Caruaru, agora, contavam com 
os subsídios eclesiásticos, institucionais e teológicos que dariam legitimidade à novel igreja. No ano seguinte, seu primeiro pastor titular foi eleito, o reverendo José Quaresma de Mendonça. Logo após, a expressão 'vale da bênção' foi retomada, desde então, se reconheceu oficialmente a Igreja Evangélica Congregacional Vale da Bênção. A comunidade composta por aproximadamente setenta membros, entrou numa fase de crescimento e expansão a partir da década de 1980.

No ano de 1986, o reverendo Nicácio Correia de Moura Filho foi empossado pastor titular da $1^{\text {a }}$ Igreja Evangélica Congregacional Vale da Bênção de Caruaru - ou, simplesmente, Vale Central. Notadamente, as atividades evangelísticas desta comunidade foram reforçadas, evidenciada pela abertura de novas congregações, pontos de pregação e, ainda, emancipação de congregações. Com a criação do Departamento de Atividades Missionárias (DEPAM), a Igreja Vale da Bênção Central contribuiu para implantação de igrejas congregacionais filiadas à Aliança Congregacional no agreste e sertão pernambucano, na região metropolitana do Recife, nos estados da Bahia, Paraíba e São Paulo (Siqueira, 2007). Sem desconsiderar a singularidade e relevância do congregacionalismo por si, a roupagem pentecostalizada e adoção de estratégias evangelísticas semelhantes aos pentecostais, indubitavelmente, contribuiu para que os congregacionais renovados crescessem numericamente e expandissem seus territórios de atuação. Atualmente, contando com cerca de quatro mil membros, distribuídos por sete igrejas e quinze congregações somente no municipio de Caruaru.

\section{Considerações finais}

Ao longo deste trabalho, buscamos refletir sobre o Movimento de Renovação Espiritual como importante componente da trajetória histórica do protestantismo e congregacionalismo no país. No entanto, permanece desconhecido por muitos pesquisadores, pouco explorado por uns e desconsiderado por outros tantos. Essa renovação religiosa, com tons e formas pentecostalizadas, parece-nos fundamental para que possamos entender determinados aspectos do campo evangélico e facetas do protestantismo brasileiro contemporâneo. Não obstante, faz-nos ponderar sobre as relações e tensões envolvendo protestantes e pentecostais. 
Tivemos por objetivo, ainda, resgatar a historicidade do congregacionalismo como segmento importante na composição do campo protestante brasileiro, porém, ainda marginalizado no âmbito acadêmico e desconhecido para muitos evangélicos. Ao tratar da Aliança Congregacional e da Igreja Vale da Bênção, procuramos oferecer ao leitor um retrato do Movimento de Renovação Espiritual, seu fenômeno adjacente e suas dobras nos níveis denominacional e comunitário. Destacando que o fenômeno pentecostalizante provocou conflitos e tensões que culminaram na criação de uma nova organização denominacional e comunidades congregacionais renovadas, nas quais o paradigma pentecostal se alinhou com a tradição congregacionalista, dando contornos à cultura e identidade congregacional carismática. Nestes termos, ancoramos a relevância de nosso estudo, esperando contribuir para compreensão socioantropológica, histórica e, quem sabe, teológica do campo evangélico, protestante e congregacional e suas interfaces com o pentecostalismo.

\section{Referências bibliográficas}

ARAÚJO, Rosivaldo de. Ninguém detém! É obra santa. João Pessoa: Ed. Betel Brasileiro, 2013.

BOURDIEU, Pierre. A economia das trocas simbólicas. São Paulo: Ed. Perspectiva, 2007.

CAMPOS, Leonildo Silveira; GUTIÉRREZ, Benjamín F. (Ed.). Na força do Espírito: Os pentecostais na América Latina. São Paulo: ALPR, 1996.

CAMPOS JÚNIOR, Luís de Castro. Pentecostalismo e transformações na sociedade brasileira: A Igreja Avivamento Bíblico. São Paulo: Annablume, 2009.

CÉSAR, Salustiano Pereira. O congregacionalismo no Brasil. Rio de Janeiro: OMEB, 1983.

EVERY-CLAYTON, Joyce Elizabeth Winifred; ARAÚJO, Marcos Robson Quaresma de. Caruaru, cem anos de luz: Primeira Igreja Evangélica Congregacional de Caruaru (1989-1998). Caruaru: Art’Berg Gráfica e Editora, 1998.

MENDONÇA, Antônio Gouvêa. A experiência religiosa e a institucionalização da religião. In: Revista Estudos Avançados, ano XVIII, n 52, ago. 2004, pp. 29-46.

MENDONÇA, Iraci Silva de. Memorial José Quaresma: 50 anos de ministério. Campina Grande: Artexpress Editora, 2007.

MORANTE, Bernardo Luis Campos. El principio pentecostalidad: la unidad en el Espiritu, fundamento de la paz. Salem (EUA): Kerigma Publicaciones, 2016. 
MOREIRA, Thiago. Da tradição à renovação na Igreja Batista da Lagoinha: um olhar sobre o protestantismo renovado. Dissertação (Mestrado em Ciência da Religião), UFJF, Juiz de Fora, 2016.

PEREIRA, Reinaldo Arruda. Igreja Batista da Lagoinha: trajetória e identidade de uma corporação religiosa em processo de pentecostalização. Tese (Doutorado em Ciências da Religião) UMESP, São Bernardo do Campo, 2011.

PORTO FILHO, Manoel da Silveira. Congregacionalismo brasileiro. Rio de Janeiro: DERP-UIECB, 1997.

RODRIGUES, Isaac Martins. História da Assembleia de Deus em Pernambuco.Recife: [s.n.], 1968.

ROLIM, Francisco Cartaxo. Pentecostais no Brasil: uma interpretação sócioreligiosa. Petrópolis: Vozes, 1985.

SANTANA FILHO, Manoel Bernardino. Um pequeno relato das relações entre a Aliança e a União das Igrejas Evangélicas e Congregacionais do Brasil. [S.1.], 2011.

SANTOS, Geraldo Batista dos. Sesquicentenário do congregacionalismo brasileiro (1855-2005). João Pessoa: JRC Editora, 2006.

SANTOS, Valter Borges dos. Origem e institucionalização da Igreja Metodista Wesleyana. Dissertação (Mestrado em Ciências da Religião) UMESP, São Bernardo do Campo, 2014.

SILVA, Gustavo Henrique. Uma Princesa Centenária: Desejos, expectativas e exclusões nas comemorações dos 100 anos de Caruaru-PE (1957). Dissertação (Mestrado em História) UFCG, Campina Grande, 2014.

SIQUEIRA, Daniel Tenório. Igreja Evangélica Congregacional Vale da Bênção: 40 anos de história. Monografia (Bacharelado Livre em Teologia) STCN, Caruaru, 2007.

SOUZA, Carlos Henrique Pereira de. Entre a capela e a catedral: tensões e reinvenções da identidade religiosa na experiência do protestantismo histórico atual. Dissertação (Mestrado em Ciências Sociais) UERJ, Rio de Janeiro, 2013.

TOGNINI, Enéas. Batismo no Espirito Santo. São Paulo: Edições Enéas Tognini, 1986.

\footnotetext{
1 O Movimento Pentecostal ou, simplesmente, pentecostalismo despontou no cenário estadunidense no início do século XX. Esse segmento protestante conjugou uma postura conservadora e, em certo sentido, literalista de interpretação bíblica; um ideário conversionista; uma compreensão escatológica pré-milenista; com crenças e práticas referentes ao ensinamento do batismo com Espírito Santo e da atualidade dos dons carismáticos registrados no Novo Testamento.

${ }^{2}$ Fazemos uso da expressão protestantismo e correlatos - e.g. protestantes históricos como tem sido usualmente aplicada na literatura acadêmica, designandoo conjunto de igrejas vinculadas teológica e historicamente com confissões protestantes originárias das reformas religiosas e/ou do período pós-reforma, dos séculos XVI e XVII.
} 
3 O Movimento de Renovação Espiritual, assim como o pentecostalismo, deu ênfase aos temas da missão evangélica, batismo do Espírito Santo e dons carismáticos e, ainda, ao retorno de Cristo. Cumpre frisar que o fenômeno da pentecostalização não incide na simples assimilação de crenças pentecostais, inclui também um resgate de ênfases doutrinárias que estiveram presentes em segmentos do protestantismo em outros momentos, especialmente, no Grandes Despertamentos ou Reavivamentos, ocorridos na Inglaterra e nos Estados Unidos, entre os séculos XVII e XIX.

${ }^{4}$ Entende-se por protestantismo de missão o conjunto de denominações implantadas no Brasil, em fins do século XIX, por meio de missionários europeus e estadunidenses. Com destaque para os batistas, congregacionais, metodistas e presbiterianos.

${ }^{5}$ União das Igrejas Evangélicas Congregacionais do Brasil, denominação que surgiu do movimento de restauração denominacional, composta majoritariamente por igrejas do Nordeste.

${ }^{6}$ Entrevista de Anacleto Inácio, pastor congregacional e professor de História do Congregacionalismo, concedida em 02 de junho de 2020.

${ }^{7}$ Entrevista de Josué Eusébio Ferreira concedida em 25 de maio de 2020.

8 Entrevista concedida ao autor em 02 de junho de 2020.

9 Essa informação extraída de Rosivaldo de Araújo (2013, p. 73-77) entra em contradição com a narrativa histórica oficial da Igreja Evangélica Congregacional Vale da Bênção e registrada por Daniel T. Siqueira (2007, p. 14) que afirmam: "Foi durante este periodo que aconteceu o $3^{\circ}$ Encontro de Renovação Espiritual, realizado na cidade de Feira de Santana-BA, no dia 21 de julho de 1967, promovido pelo pastor Rosivaldo de Araújo. O presbitero Caetano Antônio da Silva organizou um grupo e foi ao encontro". Prevendo os esforços e tempo que seriam despendidos para solucionar essa incompatibilidade, preferimos nos limitar a sublinhar essa questão com esta nota.

10 Segundo Araújo (2013), a escolha dessa temática foi baseada no texto bíblico de $2^{\circ}$ Livro das Crônicas, capítulo 20, que relata a intervenção divina para vitória dos judeus numa batalha épica. Celebrando vitoriosos, chamaram o vale onde estavam de Beraca, que traduzido do hebraico significa "bênção".

Recebido em 21/07/2021

Aceito para publicação em 19/08/2021 